\title{
Sustainable human resource management in a time of global uncertainty
}

\author{
Zuzana Dvorakova ${ }^{1, *}$ \\ ${ }^{1}$ CTU in Prague, MIAS School of Business, Kolejni 2637/2a, 16000 Prague 6, Czechia
}

\begin{abstract}
The paper characterizes the state-of-the-art knowledge of sustainable human resource management (HRM) based on on-the-desk analysis of articles in the Web of Science database published in the last two years in journals in Q1 and Q2. In the literature, sustainable HRM is considered an extension of strategic HRM with a focus on long-term human resource development, regeneration, and renewal. The current focus has been on economic, environmental aspects in HR processes, and it turns out that social sustainability remains on the edge of HR managers' interests. The situation in the Czech environment illustrates two narrative cases from March and April 2020. It becomes a challenge for all actors in education to change their view of ways of education and to accept as a necessity to apply distance education on a mass scale.
\end{abstract}

\section{Introduction}

Recently, articles on sustainable human resource management (HRM) have published. This concept of managing people is promoted, especially by "green" organizations. For the community of HR professionals and managers, it is necessary to define what dimensions and characteristics this new approach will include so that they can use in HR practices. Corporations with commitments to sustainable development goals are open to HR practices that motivate sustainable development in work incentive systems.

Research on the benefits of HRM for business and the strategic dimension of HRM today lags what business expects of it. Kaufman [1] refers to the phenomenon is as the three-decade-long psychologization of HRM, which is further deepened by scholastic scientism and normative promotionalism. Psychologization reduces explanations of macrolevel HRM outcomes to individual-level psychological-behavioral factors and individual differences. It is essential but often proclaimed in favor of an employer branding that the company creates a favorable environment for training and development. The key to deciding whether and how much to invest in people must be, what outputs will flow from the freedom given to employees to create and form the belief that their ideas will reflect in new products and services. Innovations mean a driving force to overcome the crisis, but it is necessary to ensure that the criteria for assessing their contributions to the business are a part of performance management and the basis for rewards.

\footnotetext{
* Corresponding author: zuzan.dvorak@gmail.com
} 
The paper aims to characterize the understanding of sustainable HRM, to identify the place of education in social sustainability, to illustrate on narrative cases the transition to distance education in the $\mathrm{CR}$, and to outline the prospects for online education.

\section{Theoretical ground for sustainable HRM}

\subsection{Analysis of bibliographic data}

Searching for relevant sources, it retrieved 13,110 bibliographic records that matched the query in database search in the period 1990-2020 (accessed on 2020/05/05): records from the Web of Science databases count for 5,129 and Scopus 7,981. The structure of bibliographic records shows Table 1. The enormous amount of literature of various sciences does not allow conducting a complete analysis of all of them. In this paper, the analysis is limited by the most significant works, considering two requirements:

- papers published in journals from Q1 and Q2 quartiles from last two years,

- the citation index related to strategic human resource management, green human resource management, SHRM, organizational sustainability, and social sustainability.

The study outlines the development of promising directions, mostly in management, business, applied psychology, industrial relations, economics, and social sciences.

Table 1. Bibliographic records by the query in Web of Science and Scopus database 1990-2020.

\begin{tabular}{|c|c|c|}
\hline Query & Web of Science $^{1}$ & Scopus $^{1}$ \\
\hline Strategic human resource management & 641 & 917 \\
\hline Green human resource management & 121 & 175 \\
\hline Sustainable human resource management & 64 & 78 \\
\hline Organizational sustainability & 256 & 492 \\
\hline Social sustainability & 2241 & 3046 \\
\hline Massive open online courses & 1896 & 3273 \\
\hline Total & 5129 & 7981 \\
\hline
\end{tabular}

${ }^{1}$ Source: Author. Accessed 2020/05/05.

Strategic HRM belongs to the most studied topics in the period 1990-2020 in the USA (208 publications in the Web of Science), Peoples Republic of China (118), Australia (61), England (51), Spain (32) and Germany (25). In the CR, it covers eight publications and Slovakia 3. Articles dealt with strategic HRM cover according to categories topics from management (475 publications), business (148), applied psychology (115), industrial relations and labor (85), economics (30), operations research management science, and social sciences interdisciplinary (both 29). In the case of green HRM, the order of the number of publications characterizes the following: Peoples Republic of China (25), Malaysia (20), England (16), and Brazil, France, India (each 14). The CR represents six publications and Slovakia one. Sustainable HRM is a relatively new topic and mostly written in publications from Peoples Republic of China (9), Spain (7), England (6), Lithuania and Slovakia (both 5) and only one in the CR. Publications about organizational sustainability mainly print in the USA (75), Brazil (22), England (21), Malaysia (15), India 
(14), and Peoples Republic of China (13). In the same period in Slovakia, one and nothing in the CR. They focus predominantly on management (72 publications), green sustainable science technology (61), environmental sciences, and environmental studies (both 54), and business (36). Social sustainability mostly becomes a subject of publications in the USA (314), England (234), Peoples Republic of China (190), Italy (182), Australia (169), Spain, and Sweden (both 143), but in the CR 18 and Slovakia 5. They belong to environmental sciences (599), green sustainable science technology (548), environmental studies (492), engineering environmental (178), management (172), regional urban planning (149), and urban studies (139). Massive open online courses (MOOCs) are subjects of papers published in the USA (366), Peoples Republic of China (253), Spain (214), England (152), Germany (98), and Australia (87). The CR represents ten publications and Slovakia none. Topics of papers mainly cover Web of Science categories: education and educational research (917), computer science interdisciplinary applications (306), computer science theory methods (268), scientific education disciplines (228), computer science information systems (221), engineering electrical electronic (197), and computer science artificial intelligence (126).

The number of papers increases during the last 20 years, as shown in Table 2. It demonstrates prospective potentials for innovations and competitiveness.

Table 2. Bibliographic records by the query in Web of Science database 2000-2020

\begin{tabular}{|c|c|c|c|c|c|c|c|c|c|}
\hline \multirow{2}{*}{ Query } & \multicolumn{9}{|c|}{ Years } \\
\cline { 2 - 11 } & 2000 & 2005 & 2010 & 2015 & 2016 & 2017 & 2018 & 2019 & 2020 \\
\hline Strategic HRM & 12 & 21 & 24 & 41 & 47 & 47 & 41 & 55 & 8 \\
\hline Green HRM & - & - & - & 5 & 14 & 14 & 21 & 34 & 25 \\
\hline Sustainable HRM & - & 1 & - & 1 & 4 & 7 & 8 & 30 & 10 \\
\hline $\begin{array}{c}\text { Organizational } \\
\text { sustainability }\end{array}$ & 1 & 1 & 3 & 29 & 28 & 36 & 49 & 37 & 15 \\
\hline $\begin{array}{c}\text { Social } \\
\text { sustainability }\end{array}$ & 4 & 15 & 56 & 201 & 223 & 284 & 382 & 419 & 121 \\
\hline $\begin{array}{c}\text { Massive open } \\
\text { online courses }\end{array}$ & - & - & - & 316 & 340 & 369 & 294 & 264 & 60 \\
\hline
\end{tabular}

Source: Author. Accessed 2020/05/05.

\subsection{Literature overview}

\subsubsection{Sustainable HRM - the concept and characteristics}

Sustainable HRM is seen as an extension of strategic HRM and turns into a new approach to managing people with a focus on long-term human resource development, regeneration, and renewal. However, the attributes of sustainable HRM are not explicit [2]. Chams and Garcia-Blandon [3] summarize their findings of sustainable HRM, arguing that it plays a crucial role in developing a sustainable work environment and in facilitating the attainment of sustainable development goals. Therefore, the main themes in the field of sustainable HRM are environmental management, socially responsible HRM, and turnover [4].

Attentions for sustainability activities of corporations evoke green HRM. Amrutha and Geetha [5] characterize green HR practices, employee green behavior at the workplace, and organizational sustainability and argue that social sustainability is the least explored area than economic and environmental pillars of sustainability. 
Macke and Genari [6] focus on the state-of-the-art of sustainable HRM. They believe that four categories emerge to describe its strategy, namely: sustainable leadership; the relationship among HRM, environmental sustainability, and organizational performance; the tensions and paradoxes between HRM practices and sustainability, and the link between HRM and the social dimension of sustainability. However, it is rare to find the managerial meaning of sustainable HRM. Finish top managers describe the theme in four dimensions justice and equality, transparent HR practices, profitability, and employee well-being, and four broader responsibility areas: legal and ethical, managerial, social, and economic [7].

Roca-Puig [8] identifies on an extensive longitudinal data set that HR investment strategy negatively affects income inequality and that corporate decisions on social sustainability can influence social sustainability in society. So, the norm of a circular or two-way relationship between business and society builds social sustainability by increasing trust and cooperation in any group of people. One of the main drivers to generate social sustainability is knowledge sharing behavior [9]. In the case that employees are willing to cooperate and share in fair organizational contexts, when they feel satisfied and affectively committed, and when they get fair rewards for their contributions (Ibid.). However, HR professionals and managers must involve in developing sustainable HRM. If they perceive their role in the business as meaningful and going beyond the sole focus on economic performance, then they can achieve higher job satisfaction and have lower intention to leave [10].

Even though the number of papers about sustainable HRM and organizational sustainability is growing (as shown above in Table 2), literature review remains substantially unclear in which HR practices present a basis for sustainable leading and managing people. Aimed at innovation behavior, employee engagement, and retention, the significant practices for their long-term achievement consist of organizational fairness, the quality of relations between supervisors and subordinates, performance appraisal, pay-forperformance, and work-life environment.

Sustainable HRM underlines the involvement of partnerships and external relations in learning and personal development processes [11]. Based on the literature review, they believe that a crucial role must play innovations in education and development as their HR practices open mind for creativity and successful adaptation to changes in the labor world [Ibid.].

\subsubsection{Sustainable HRM in the cultural contexts}

Culture plays a significant role, and organizations demonstrate their influence in developing HR strategies and day-to-day activities. Challenges for implementing HRM activities across borders must mainly tackle multinational enterprises (MNEs) because they operate in culturally different contexts. They must decide whether to standardize or localize their processes and to improve the quality of working life and work environment $[12,13,14,15$, 16]. In the expatriation strategies of MNEs, differences depend on the internationalization of the MNE and disparities in industrial relations between the parent and subsidiary's environment [17]. The most critical practices in managing people cover performance management, compensation, and industrial relations.

Findings of a large scale set of employer-employee data in 14 countries confirm a positive relationship between HR practices combined in high-performance work systems and organizational performance across societal cultures [18]. Based on the research mentioned above, it is evident two paradoxes, namely the co-existence of both process and result-focused orientations and both normative and pragmatic approaches to managing people [19, 20]. Findings achieved by Gu, Nolan, and Rowley [21] reveal about organizational justice in performance appraisal processes a necessity when analyzing three 
different types of banks in China, i.e., the state-owned bank, the city-commercial, and foreign-owned counterparts. They argue that it is time to re-evaluate the assumption that national culture variables are incredibly stable and have universal explanatory value in all organizational contexts.

HR practices labeled as high-performance work practices (HPWPs) are affected by national cultural dimensions [22]. However, these HR practices are not analyzed in literature from cross-cultural HR management aimed at understanding of the role of national culture on the effectiveness of HPWPs (Ibid.). Another example of a widely accepted perception can be about benefits stemming from performance appraisal, productive relationship between performance-based rewards, and innovative behavior. Research done by Curzi, Fabbri, Scapolan, and Boscolo [23] shows that formal performance appraisal probably reduces the promotion of individual innovation and creativity at work. Large scale research across ten countries about the relationship between performance-based rewards and innovative behavior confirmed no dependence of rewards on behavior that generates innovations [24]. Country specifics exist in the case of individualized pay-for-performance schemes for employees, even though this practice seems to be a standard tool for work motivation. Its implementation determinates either cultural and institutional factors at the country level, and senior managers' agency. So, in the USA, the adoption of these schemes is rather useful than in many other countries [25].

Summarizing: The least analyzed area of sustainable HRM belongs to social sustainability. The crucial role in HRM for mastering challenges must play innovations in education and development. Organizational preconditions for building the creative atmosphere include friendly and knowledge sharing environment, trust and cooperation between supervisors and subordinates, informal feedback about performance, massive open access to learning across borders, and opportunities for using new skills at work.

\section{Methodology and findings}

\subsection{Methodology}

The methodology insists on several methods that enable a triangular analysis. The research combines state-of-the-art knowledge identified by in-depth-analysis of secondary sources, i.e., papers indexed in Web of Science and Scopus in 2018-2020, with two semi-structured interviews held in March and April 2020. The semi-structured interviews use due to the possibilities to address one managerial respondent, one teacher, and the author's observations. They provide information for writing two narrative cases.

The reasoning methods are first that ethical aspects of sustainable HRM as it deals with social phenomena, which is deeply rooted in history, culture, values, and behaviors, and the business reality loves to apply pragmatic HR practices. Secondly, based on bibliometric analysis, it is evident a need to formulate how and which tools can support a change in employees' attitudes to MOOCs. Therefore, research collects and analyses data by an interpretative group of methods that reveal the meaning-making practices of human subjects to get a basis for achieving results, emerging questions for the practice, and ideas for future research.

\subsection{Narrative cases}

Case study 1 . Helena, 57, professor, university.

From the second week of March, we learned how to teach online and work from the home office. The mistake was that we had no idea which platforms to use and which ones 
posed a cyber risk. In March, the Ministry of Education, Youth and Sport organized webinars about contactless teaching. The employer-provided two online pieces of training for beginners in MS Teams. However, a real benefit for acquiring new skills has been a shared experience among teachers. As of April, only Moodle and MS Teams can use it at the university. Most of the colleagues managed to teach remotely during the first three weeks after the declaration of the state of emergency. Teaching takes place according to the original schedule, and gradually both teachers and students have gained a routine in the use of Teams. During the lessons, we can monitor and save how many students and who connect to the ongoing lesson, participants can ask questions through a microphone, open a video camera, actively participate in the course of lessons, and use chat. In March and April, I followed students' attitudes to online teaching in the case of three subjects with a total of 150 students, totally, for five weeks using MS Teams, Moodle, and emails. The data monitor the number of students joined, the development of the connected students during the class, and their activities. The teaching took place according to the schedule from the time of contact teaching. For a given period, the number of connected ones remains constant. Roughly $1 / 3$ of the students enrolled in the courses never joined the meetings, even if they have received an invitation, and a minimum of those joined meetings participated in the discussion. Nobody used the offer of individual online consultations.

Case study 2. Pavel, 56, managing partner, a multinational consultancy firm.

The consultancy firm operates in seven European countries and has got five branches outside Europe. The company specializes in corporate training and development, coaching, and designing compensation. The Czech subsidiary belongs to the micro-enterprise category and cooperates in the frame of an extensive network of freelance consultants. Clients stopped contracted pieces of training from 16 March. However, some of them, mainly clients outside the CR, asked for using online training, like appraisal interviews. Challenges were which applications can be useful, user friendly, and safe in such training. Clients preferred MS Teams, Google Hangouts, or Webex. The scope of clients willing to use online training is slightly rising as the Czech team consists of diverse consultants who speak fluent English, and the company has an excellent long-term reputation. On the side of the consultancy firm, the situation looks as opportunities for development in several areas; even it was tough to reduce personnel costs and find ways how to work from the home office effectively. All consultants struggle with an unpleasant form of training as they must speak and behave without social contacts, especially, it is difficult for less experienced trainers. The future will build on high staff retention, flexible working regime, home office, diverse team, and their language skills. The intention is to provide both traditional and online training plus to design some training as sophisticated MOOCs.

\section{Discussion and conclusion}

The Czech society places the primary responsibility for the failure of pupils and students on the shoulders of teachers: stakeholders have an opinion that teachers are responsible for if pupils and students do not know and have little interest in learning. During a state of emergency, both sides of the educational process entered the online environment unexpectedly. The families received an experience that children who go to school mean additional work in caring for them at home. In the process of transforming teaching, educators had to rely on themselves and their schools to handle challenges. They started to work from home because the employers often have trouble providing adequate technical support, such as PC, software, a reliable Internet connection. They often remained alone and have no one to turn to for advice or have no trainers on how to teach online. Those who were trainers at the beginning of March were very overwhelmed with questions and stopped gradually answered. 
Teachers' experience can serve as a starting point for the creation and implementation of MOOCs in the Czech environment. They experience that the widening of social differences between people is accelerating. The future will depend on the technical equipment of households, the quality of the Internet connection, and the family care regarding education. The opening of the scissors will reflect on the level of education of the population. In addition to the technical side of prospective MOOCs, it is evident that the employability and job applicant success in the labor market will depend on the individual's motivation to learn. Students joined in meeting courses are mostly passive, reluctant to speak through the microphone and unwillingness to open the camera when speaking, i.e., they play a game the best thing is to remain anonymous.

There can identify several reasons for not accepting online teaching in the last two months. They range from the low attractiveness of the subject, imperfect forms of teaching, and the little experience of teachers to teach without impersonal contact when it is not possible to build social contacts and respond to non-verbal communication. Some of these negatives can address and eliminate. Another issue of contactless teaching exists that two groups of people polarize: those who want to learn and those who want to have fun enjoying the free regime at school. For university graduates, the level of motivation to learn may apply as personal responsibility for self-education when assessing job seekers. If anybody is interested in learning and see it as an inner motive, it is highly probable that such an orientation will remain as life-long characteristics. A definite group of students can distinguish for whom the study at a university is a burden; the only stimulus is the vision achieving an elite status thanks to the title, which becomes more accessible to get in these days than ever before by reducing knowledge requirements due to shortcomings of contactless teaching and testing.

\section{References}

1. B.E. Kaufman, The real problem: the deadly combination of psychologization, scientism, and normative promotionalism takes strategic human resource management down a 30-year dead end. Human Resource Management Journal 30, 49-72 (2020)

2. Z. Stankeviciute, A. Savaneviciene, Designing sustainable HRM: the core characteristics of emerging field. Sustainability 10, 4798 (2018)

3. N. Chams, J. Garcia-Blandon, On the importance of sustainable human resource management for the adoption of sustainable development goals. Resources Conservation and Recycling 141, 109-122 (2019)

4. M. Santana, A. Lopez-Cabrales, Sustainable development and human resource management: a science mapping approach. Corporate Social Responsibility and Environmental Management 26, 1171-1183 (2019)

5. V.N. Amrutha, S.N. Geetha, A systematic review on green human resource management: implications for social sustainability. Journal of Cleaner Production 247, $119131(2020)$

6. J. Macke, D. Genari, Systematic literature review on sustainable human resource management. Journal of Cleaner Production 208, 806-815 (2019)

7. M. Jaerlstrom, E. Saru, S. Vanhala, Sustainable human resource management with salience of stakeholders: a top management perspective. Journal of Business Ethics 152, 703-724 (2018)

8. V. Roca-Puig, The circular path of social sustainability: an empirical analysis. Journal of Cleaner Production 212, 916-924 (2019)

9. N. Cuguero-Escofet, P. Ficapal-Cusi, J. Torrent-Sellens, Sustainable human resource management: how to create a knowledge sharing behavior through organizational 
justice, organizational support, satisfaction, and commitment. Sustainability 11, 5419 (2019)

10. M. Guerci, A. Decramer, T. Van Waeyenberg, I. Aust, Moving beyond the link between HRM and economic performance: a study on the individual reactions of HR managers and professionals to sustainable HRM. Journal of Business Ethics 160, 783800 (2019)

11. K. Stachova, J. Papula, Z. Stacho, L. Kohnova, External partnerships in employee education and development as the key to facing Industry 4.0 challenges. Sustainability 11, 345 (2019)

12. G.C. Banks, H.M. Woznyj, R.S. Wesslen, K.A. Frear, G. Berka, E.D. Heggestad, H.L. Gordon, Strategic recruitment across borders: an investigation of multinational enterprises. Journal of Management 45, 476-509 (2019)

13. C.L. Jiang, D. Yahiaoui, French multinational companies' HRM in China: strategic orientation and integration approaches. Asia Pacific Business Review 25, 3-18 (2019)

14. H.C. Chao, A.M. Morrison, B.H. Wu, All work and no play? Antecedents of the leisure involvement of Taiwan expatriate managers in Mainland China. International Journal of Manpower 40, 1215-1238 (2019)

15. G. Hong, E. Kim, How to attract talented expatriates: the key role of sustainable HRM. Sustainability 11, 5373 (2019)

16. P. Poisat, M.R. Mey, G. Sharp, Do talent management strategies influence the psychological contract within a diverse environment? SA Journal of Human Resource Management 16, a1044 (2018)

17. J. Meuer, M. Kluike, U. Backes-Gellner, K. Pull, Using expatriates for adapting subsidiaries' employment modes to different market economies: a comparative analysis of US subsidiaries in Germany, the UK and Switzerland. European Journal of International Management 13, 328-353 (2019)

18. Dastmalchian, N. Bacon, N. McNeil, C. Steinke, P. Blyton, M.S. Kumar, S. Bayraktar, W. Auer-Rizzi, A.A. Bodla, R. Cotton, et al., High-performance work systems and organizational performance across societal cultures. Journal of International Business Studies (Jan 2020)

19. A. Erthal, L. Marques, National culture and organizational culture in lean organizations: a systematic review. Production Planning \& Control 29, 668-687 (2018)

20. M. Furusawa, Ch. Brewster, Japanese self-initiated expatriates as boundary spanners in Chinese subsidiaries of Japanese MNEs: Antecedents, social capital, and HRM practices. Thunderbird International Business Review 60, 911-919 (2018)

21. F. Gu, J. Nolan, Ch. Rowley, Organizational justice in Chinese banks: understanding the variable influence of guanxi on perceptions of fairness in performance appraisal. Asia Pacific Business Review (Dec 2019)

22. S. Nadeem, M. Raza, N. Kayani, A. Aziz, D. Nayab, Examining cross-cultural compatibility of high-performance work practices. International Business Review 27, 563-583 (2018)

23. Y. Curzi, T. Fabbri, A.C. Scapolan, S. Boscolo, Performance appraisal and innovative behavior in the digital era. Frontiers in Psychology 10, 1659 (2019)

24. K. Sanders, F. Jorgensen, H. Shipton, Y. Van Rossenberg, R. Cunha, X.B. Li, R. Rodrigues, S.I. Wong, A. Dysvik, Performance-based rewards, and innovative behaviors. Human Resource Management 57, 1455-1468 (2018)

25. P. Gooderham, M. Fenton-O'Creevy, R. Croucher, M. Brookes, A multilevel analysis of the use of individual pay-for-performance systems. Journal of Management 44, 1479-1504 (2018) 